\title{
Evolution of Microstructure in a Cu-Cr in situ Composite Produced by Thermo-Mechanical Processing
}

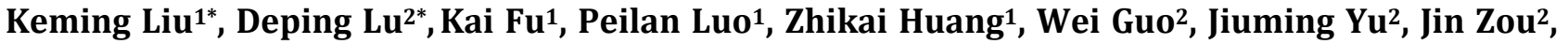 \\ Qiang $\mathrm{Hu}^{2}$
}

${ }^{1}$ Jiangxi Key Laboratory for Precision Drive and Control, Nanchang Institute of Technology, Nanchang, China

${ }^{2}$ Jiangxi Key Laboratory for Advanced Copper and Tungsten Materials, Jiangxi Academy of Sciences, Nanchang, China

Email: *jokeyliu@163.com, 1lludp@163.com

How to cite this paper: Liu, K.M., Lu, D.P., Fu, K., Luo, P.L., Huang, Z.K., Guo, W., Yu, J.M., Zou, J. and Hu, Q. (2017) Evolution of Microstructure in a $\mathrm{Cu}-\mathrm{Cr}$ in situ Composite Produced by Thermo-Me-chanical Processing. Journal of Materials Science and Chemical Engineering, 5, 29-35.

https://doi.org/10.4236/msce.2017.57004

Received: May 10, 2017

Accepted: July 4, 2017

Published: July 7, 2017

\begin{abstract}
This paper studied the microstructure evolution of a deformation-processed $\mathrm{Cu}-7 \mathrm{Cr}$ in situ composite prepared by thermo-mechanical processing. The longitudinal and transverse sectional microstructures were analyzed using an optical microscope and a scanning electronic microscope. In the longitudinal section, the initially randomly distributed $\mathrm{Cr}$ dendrites in the as-cast $\mathrm{Cu}-7 \mathrm{Cr}$ alloy were transformed into the fibres aligned parallel to the drawing axis; the $\mathrm{Cr}$ dendrites experienced breaking, flattening and rotating, lapping and merging, and homogenizing and refinement during thermo-mechanical processing. In the transverse section, the initially randomly distributed $\mathrm{Cr}$ dendrites in the as-cast $\mathrm{Cu}-7 \mathrm{Cr}$ alloy were changed into the curvy ribbon like fibres; the $\mathrm{Cr}$ dendrites underwent breaking, flattening and rotating, folding and twisting, and irregularizing and refinement during thermo-mechanical processing.
\end{abstract}

\section{Keywords}

$\mathrm{Cu}-\mathrm{Cr}$, in situ Composite, Evolution, Microstructure, Thermo-Mechanical Processing

\section{Introduction}

Over the past several decades, deformation-processed binary $\mathrm{Cu}$-based in situ composites such as $\mathrm{Cu}-\mathrm{Fe}, \mathrm{Cu}-\mathrm{Ag}, \mathrm{Cu}-\mathrm{Nb}$, and $\mathrm{Cu}-\mathrm{Cr}$ have been the subject of extensive research due to their high strength and good conductivity [1] [2] [3] [4] [5]. However, the $\mathrm{Cu}-\mathrm{Fe}$ in situ composite has relatively low conductivity due to the relatively high solubility of $\mathrm{Fe}$ in the $\mathrm{Cu}$ matrix and the particularly 
harmful effect on the conductivity of Fe atoms in solid solution [6]. Ag and $\mathrm{Nb}$ are expensive metals, which impede the use of the $\mathrm{Cu}-\mathrm{Ag}$ and $\mathrm{Cu}-\mathrm{Nb}$ in situ composites in large-scale applications. The $\mathrm{Cu}-\mathrm{Cr}$ in situ composite is of particular interest due to the relatively economical cost and the high strength of $\mathrm{Cr}$, and the limited solubility of $\mathrm{Cr}$ in the $\mathrm{Cu}$ matrix [7] [8].

The deformation-processed $\mathrm{Cu}-\mathrm{Cr}$ in situ composite belong to the class of bulk nanostructured metallic materials, due to the small size of the structural constitutes produced via the in situ deformation processing. The $\mathrm{Cr}$ fibres formed in the $\mathrm{Cu}$ matrix ensure the high tensile strength, and the limited solubility of $\mathrm{Cr}$ atoms in the $\mathrm{Cu}$ matrix ensures the high electrical conductivity. The filamentary structure of double phases in the $\mathrm{Cu}-7 \mathrm{Cr}$ in situ composite was produced by severe cold drawing and intermediate heat treatment. The constituent concentration, cold drawing strain and heat treatment parameter strongly influence the properties [9] [10] [11]. In special, the microstructure evolution during cold drawing plays an important role in the change of the strength and conductivity with the cold drawing strain. Stepanov et al. [12] investigated the evolution of microstructure and mechanical properties in a $\mathrm{Cu}-14 \mathrm{Fe}$ in situ composite, and found that rolling resulted in significant microstructural refinement of the $\mathrm{Cu}-14 \mathrm{Fe}$ alloy. The work of Liu et al. [13] suggested that the eutectic colonies in $\mathrm{Cu}-\mathrm{Ag}$ in situ composites were evolved into filamentary bundles with tight arrangement of double phases during severe cold drawing.

However, the evolution of microstructure in $\mathrm{Cu}-\mathrm{Cr}$ in situ composites still needs further investigation because of the complex co-deformation of $\mathrm{Cu}$ and $\mathrm{Cr}$ phases. In this work, the as-cast and deformation-processed microstructures of a $\mathrm{Cu}-7 \mathrm{Cr}$ in situ composite were investigated. The microstructure evolution during cold drawing was analyzed.

\section{Experimental Details}

The $\mathrm{Cu}-7 \mathrm{wt} \% \mathrm{Cr}$ (designated $\mathrm{Cu}-7 \mathrm{Cr}$ ) alloy was produced by melting appropriate amounts of electrolytic $\mathrm{Cu}$ and commercial $\mathrm{Cr}$ (of at least 99.9 wt.\% purity) using a magnesia crucible in a vacuum induction furnace, and was casted into rod ingots of diameter, $\mathrm{d}=36 \mathrm{~mm}$. The deformation-processed $\mathrm{Cu}-7 \mathrm{Cr}$ in situ composite was prepared by homogenization treatment, hot rolling, heat treatment and cold drawing to a cumulative cold deformation strain of $\eta=8$. The cumulative cold deformation strain $\eta$ was obtained in terms of true strain as follows:

$$
\eta=\ln \left(A_{0} / A_{f}\right) .
$$

where $A_{0}$ is the initial transverse sectional area after hot rolling, and $A_{\mathrm{f}}$ is the final transverse sectional area after cold drawing. The detailed production processing has been published elsewhere [14]. The subsequent thermo-mechanical processing of the in situ composite of $\eta=7$ was as follows: (i heat treated at $625^{\circ} \mathrm{C}$ for $1 \mathrm{~h}$, (ii cold drawn to $\eta=8$.

The as-cast and deformation-processed samples were sectioned and the lon- 
gitudinal and transverse sectional microstructures were examined using a Leica DMI5000 M optical microscope (OM) and a JSM-6360LV scanning electronic microscope (SEM). The samples were prepared by standard mechanical polishing and were etched in a solution of $120 \mathrm{ml} \mathrm{H} 2 \mathrm{O}, 20 \mathrm{ml} \mathrm{HCl}$ and $5 \mathrm{~g} \mathrm{FeCl} 3$ to reveal the $\mathrm{Cr}$ phase structure, prior to the OM and SEM examinations

\section{Results and Discussion}

\subsection{Longitudinal Sectional Microstructure}

Figure 1(a) shows the longitudinal sectional microstructure of the as-cast $\mathrm{Cu}-7 \mathrm{Cr}$ alloy. The secondary phase $\mathrm{Cr}$ dendrites were evenly distributed in the $\mathrm{Cu}$ matrix and randomly oriented with respect to the ingot axis. Figure 1(b) shows the longitudinal sectional microstructure of the $\mathrm{Cu}-7 \mathrm{Cr}$ alloy after hot rolling. The $\mathrm{Cr}$ dendrites were broken and changed into rod like and disk like $\mathrm{Cr}$ grains. However, the size and distribution of the $\mathrm{Cr}$ phase is no obvious change. Figure 1(c) shows the longitudinal sectional microstructure of the deformationprocessed $\mathrm{Cu}-7 \mathrm{Cr}$ in situ composite with a cumulative cold deformation strain $\eta$ $=4$. There were the $\mathrm{Cu}$ matrix plus elongated $\mathrm{Cr}$ grains and thin $\mathrm{Cr}$ fibres parallel to the drawing direction. The deformation of the $\mathrm{Cr}$ grains in the $\mathrm{Cu}-7 \mathrm{Cr}$ was not uniform; there were still some tadpole-like $\mathrm{Cr}$ grains. Figure $1(\mathrm{~d})$ shows the longitudinal sectional microstructure of the deformation-processed $\mathrm{Cu}-7 \mathrm{Cr}$ in situ composite with a cumulative cold deformation strain $\eta=8$. The tadpole-like $\mathrm{Cr}$ grains in the $\mathrm{Cu}-7 \mathrm{Cr}$ in situ composite with $\eta=4$ had been all drawn into long thin fibres. The size and spacing of the $\mathrm{Cr}$ fibres in the $\mathrm{Cu}-7 \mathrm{Cr}$ in situ composite with $\eta=8$ were finer and smaller than those with $\eta=4$. The microstructure evolution of the deformation-processed $\mathrm{Cu}-7 \mathrm{Cr}$ in situ composite is

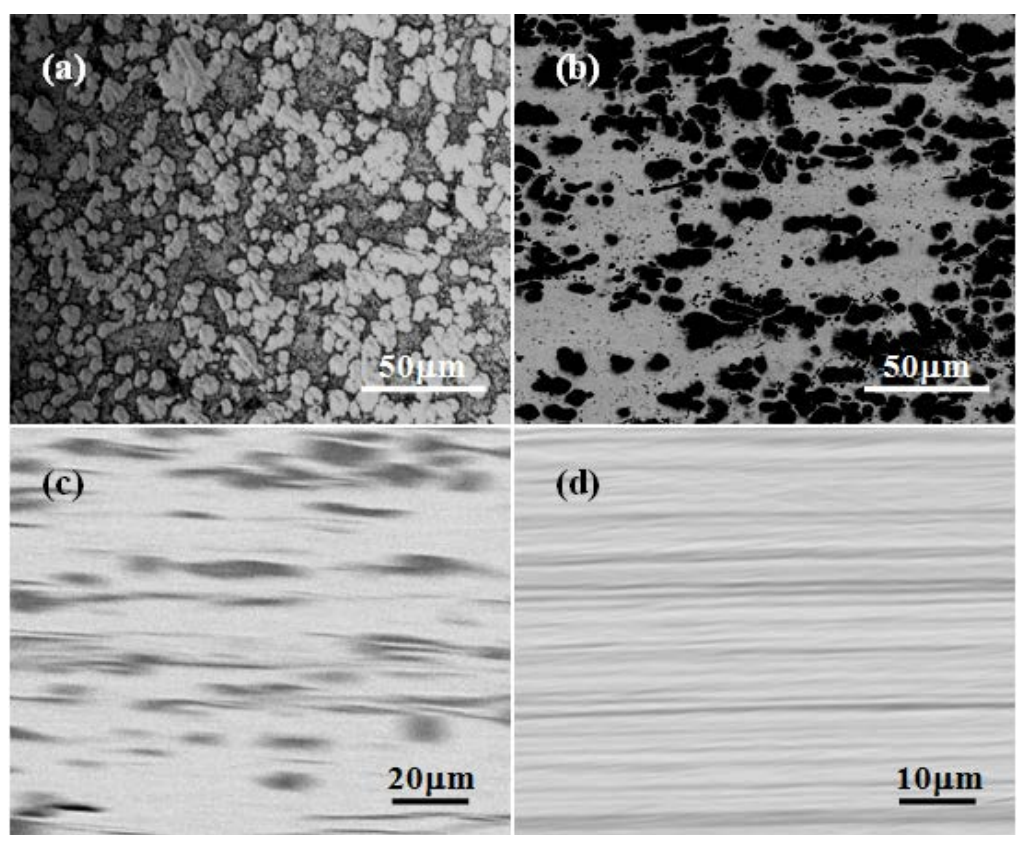

Figure 1. Longitudinal sectional microstructures of the $\mathrm{Cu}-7 \mathrm{Cr}$ alloy: (a) as-cast; (b) hot rolling; (c) $\eta=4$; (d) $\eta=8$. 
similar to those reported in previous research [9] [10] [15]. Figure 2 shows the schematic diagram of formation of fibres in deformation-processed $\mathrm{Cu}$-based in situ composites along the longitudinal section. The hot deformation broke the dendrites to form the rod like and disk like grains, as presented in Figure 2(a). The cold drawing flattened the grains and rotated the grains parallel to the drawing axis, as presented in Figure 2(b). With increasing cumulative cold deformation strain, the flattened and rotated grains were lapped and merged into fibres, as presented in Figure 2(c). With further cold drawing, the lapped and merged fibres were further refined and homogenized, as presented in Figure 2(d). The initially randomly distributed secondary dendrites in the as-cast microstructure were transformed into fibres aligned parallel to the drawing axis, with fibre aspect ratio increasing with increasing $\eta$.

\subsection{Transverse Sectional Microstructure}

Figure 3(a) shows the transverse sectional microstructure of the as-cast $\mathrm{Cu}-7 \mathrm{Cr}$ alloy. Similar to the longitudinal sectional microstructure, there were the $\mathrm{Cu}$ matrix and randomly oriented $\mathrm{Cr}$ dendrites. Figure 3(b) shows the transverse sectional microstructure of the $\mathrm{Cu}-7 \mathrm{Cr}$ alloy after hot rolling. Similar to the longitudinal sectional microstructure, there were rod and disk like $\mathrm{Cr}$ grains in the $\mathrm{Cu}$ matrix. Figure 3(c) shows the transverse sectional microstructure of the deformation-processed $\mathrm{Cu}-7 \mathrm{Cr}$ in situ composite with a cumulative cold deformation strain $\eta=4$. There were circular $\mathrm{Cr}$ grains and ribbon like $\mathrm{Cr}$ fibres in the $\mathrm{Cu}$ matrix. Figure 3(d) shows the transverse sectional microstructure of the deformation-processed $\mathrm{Cu}-7 \mathrm{Cr}$ in situ composite with a cumulative cold deformation strain $\eta=8$. The circular $\mathrm{Cr}$ grains in the $\mathrm{Cu}-7 \mathrm{Cr}$ in situ composite with $\eta$ $=4$ had been all changed into ribbon like fibres. The size and spacing of the ribbon like $\mathrm{Cr}$ fibres in the $\mathrm{Cu}-7 \mathrm{Cr}$ in situ composite with $\eta=8$ were finer and smaller than those with $\eta=4$. The ribbon like morphology is attributed to the deformation producing $\mathrm{Cr}$ fibres with a $<111>$ fibre texture, which promoted plane strain deformation rather than axially symmetric flow. However, the $\mathrm{Cu}$ matrix did deform in an axially symmetric manner during wire drawing, which

(a)

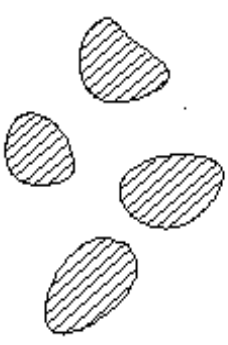

B reaking (b)

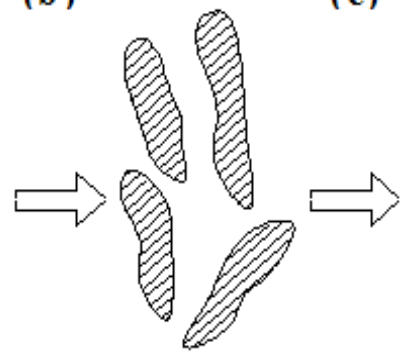

Flattening, rotating (c)

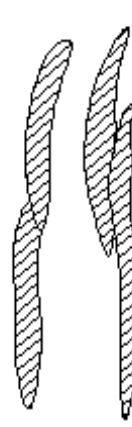

Lap ping, merging (d)

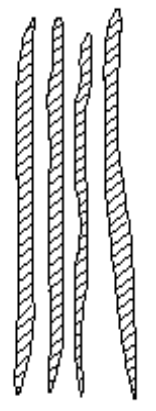

H o mogenizing

Figure 2. Schematic diagram of formation of fibres in deformation-processed Cu-based in situ composites along the longitudinal section: (a) breaking of dendrites; (b) flattening and rotating of grains; (c) lapping and merging of fibres; (d) homogenizing of fibres. 
constrained and forced the $\mathrm{Cr}$ fibres to fold or twist about the wire axis to maintain compatibility with the matrix and produced the irregular transverse section [16]. Figure 4 shows the schematic diagram of formation of fibres in deformation-processed $\mathrm{Cu}$-based in situ composites along the transverse section. Similar to the longitudinal section, the hot deformation formed the rod like and disk like grains, and the cold drawing flattened and rotated the grains parallel to the drawing axis, as presented in Figure 4(a) and Figure 4(b). With increasing cumulative cold deformation strain, the flattened and rotated grains were folded and twisted into curvy ribbon like fibres, as presented in Figure 4(c). With further cold drawing, the folded and twisted fibres were further refined and irregularized, as presented in Figure 4(d). The initially randomly distributed secondary dendrites in the as-cast microstructure were changed into curvy ribbon like fibres, with fibre aspect ratio increasing with increasing $\eta$.

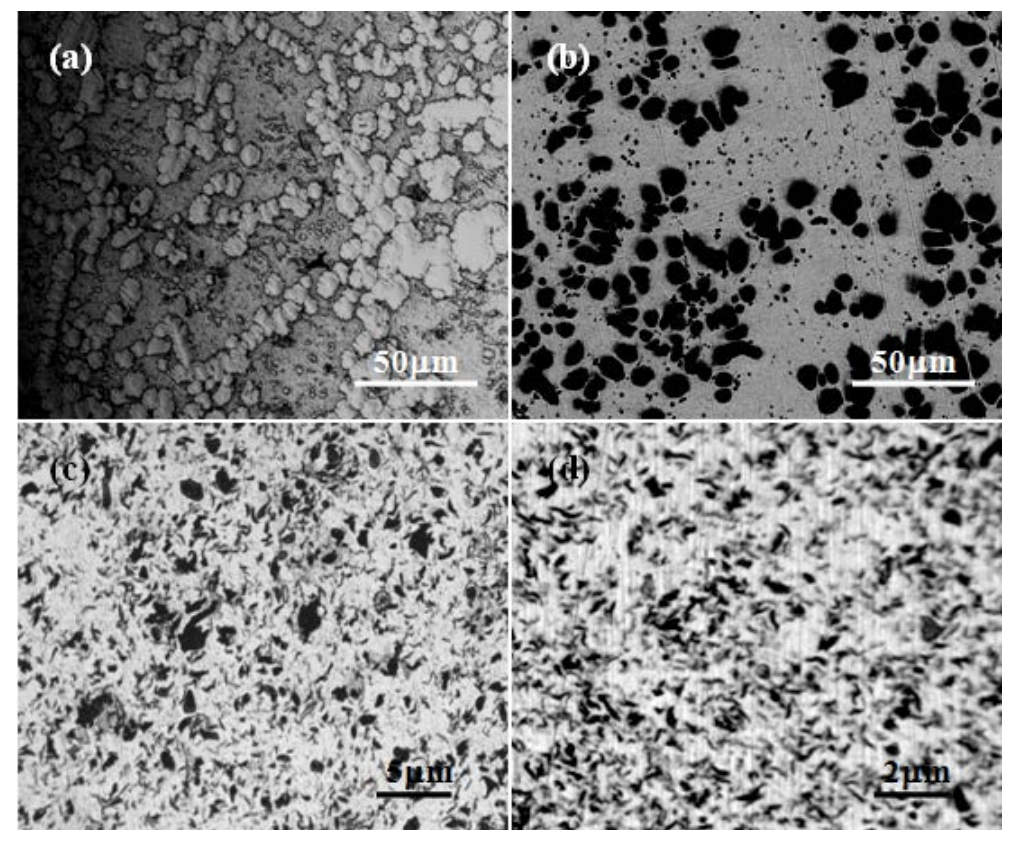

Figure 3. Transverse sectional microstructures of the $\mathrm{Cu}-7 \mathrm{Cr}$ alloy: (a) as-cast; (b) hot rolling; (c) $\eta=4$; (d) $\eta=8$.

(a)

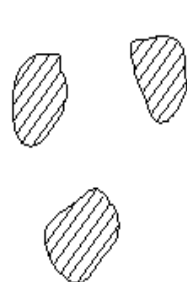

Breaking (b)

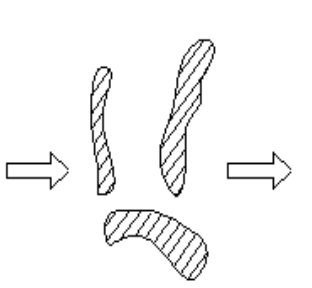

Flattening, rotating (c)

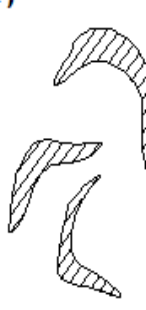

(d)

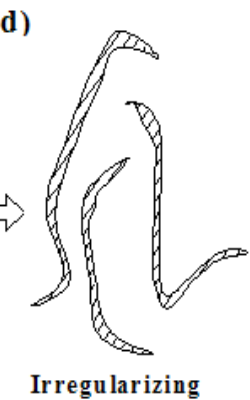

Figure 4. Schematic diagram of formation of fibres in deformation-processed $\mathrm{Cu}$-based in situ composites along the transverse direction: (a) breaking of dendrites; (b) flattening and rotating of grains; (c) folding and twisting of fibres; (d) irregularizing of fibres. 


\section{Conclusions}

1) In the longitudinal section, the initially randomly distributed $\mathrm{Cr}$ dendrites in the as-cast $\mathrm{Cu}-7 \mathrm{Cr}$ alloy were transformed into the fibres aligned parallel to the drawing axis.

2) The longitudinal sectional microstructure of the in situ composite experienced breaking of dendrites, flattening and rotating of grains, lapping and merging of fibres, and homogenizing of fibres during thermo-mechanical processing.

3) In the transverse section, the initially randomly distributed $\mathrm{Cr}$ dendrites in the as-cast $\mathrm{Cu}-7 \mathrm{Cr}$ alloy were changed into the curvy ribbon like fibres.

4) The transverse sectional microstructure of the in situ composite underwent breaking of dendrites, flattening and rotating of grains, folding and twisting of fibres, and irregularizing of fibres during thermo-mechanical processing.

\section{Acknowledgements}

This work was supported by the National Natural Science Foundation of China (51461018; 51561010), the International Science and Technology Cooperation Project of Jiangxi Province (20151BDH80006), the Prior Science and Technology Program Led by the Returned Overseas Chinese Talents (RSTH[2015]192GRSZ[2015]273), the Key Program of Natural Science Foundation of Jiangxi Province (20133BAB20008; 20144ACB20013), the Science and Technology Project of ShenZhen (JCYJ20150525092941012), and the Science and Technology Innovation Project of Jiangxi Academy of Sciences (2013-YYB-1; 2013XTPH1-19; 2015XTTD04).

\section{References}

[1] Grillo, G., Liu, K.M., Jiang, Z.Y., Zhao, J.W., Zou, J., Lu, L. and Lu, D.P. (2015) Thermal Stability and Properties of Deformation-Processed Cu-Fe in situ Composites. Metall. Mater. Trans. A, 46, 2255-2261. https://doi.org/10.1007/s11661-015-2791-x

[2] Rdzawski, Z., Głuchowski, W., Stobrawa, J., Kempiński, W. and Andrzejewski, B. (2015) Microstructure and Properties of $\mathrm{Cu}-\mathrm{Nb}$ and $\mathrm{Cu}-\mathrm{Ag}$ Nanofiber Composites. Arch. Civ. Mech. Eng., 15, 689-697. https://doi.org/10.1016/j.acme.2014.12.002

[3] Primorac, M.M., Abad, M.D., Hosemann, P., Kreuzeder, M., Maier, V. and Kiener, D. (2015) Elevated Temperature Mechanical Properties of Novel Ultra-Fine Grained Cu-Nb Composites. Mater. Sci. Eng. A, 625, 296-302. https://doi.org/10.1016/j.msea.2014.12.020

[4] Liu, K.M., Jiang, Z.Y., Zhao, J.W., Zou, J., Chen, Z.B. and Lu, D.P. (2014) Effect of Directional Solidification Rate on the Microstructure and Properties of Deformation-Processed Cu-7Cr-0.1Ag in situ Composites. J. Alloys Compd., 61, 2221-2226.

[5] Peng, L.M., Mao, X.M., Xu, K.D. and Ding, W.J. (2005) Property and Thermal Stability of in situ Composite Cu-Cr Alloy Contact Cable. J. Mater. Proc. Technol., 166, 193-198. https://doi.org/10.1016/j.jmatprotec.2004.08.013

[6] Liu, K.M., Lu, D.P., Zhou, H.T., Atrens, A., Zou, J., Yang, Y.L. and Zeng, S.M. (2010) Effect of Ag Micro-Alloying on the Microstructure and Properties of Cu-14Fe in situ Composite. Mater. Sci. Eng. A, 527, 4953-4958. 
https://doi.org/10.1016/j.msea.2010.04.051

[7] Liu, K.M., Lu, D.P., Zhou, H.T., Yang, Y.L., Atrens, A. and Zou, J. (2013) Microstructure and Properties of a Deformation-Processed $\mathrm{Cu}-\mathrm{Cr}-\mathrm{Ag}$ in situ Composite by Directional Solidification. J. Mater. Eng. Perform., 22, 3723-3727.

https://doi.org/10.1007/s11665-013-0698-5

[8] Lee, K.L. (2004) The Thermo-Mechanical Behaviour of Cu-Cr In-Situ Composite. J. Mater. Sci., 39, 3047-3055. https://doi.org/10.1023/B:JMSC.0000025831.58057.52

[9] Que, Z.P., Lee, J.H., Jung, H.M., Shin, J.H., Han, S.Z. and Euh, K.J. (2013) Microstructure evolution in $\mathrm{Cu}-1.54 \mathrm{wt} \% \mathrm{Cr}$ alloy during directional solidification. J. Cryst. Growth, 362, 58-61. https://doi.org/10.1016/j.jcrysgro.2011.12.083

[10] Liu, J.B., Zhang, L., Yao, D.W. and Meng, L. (2011) Microstructure Evolution of $\mathrm{Cu} / \mathrm{Ag}$ Interface in the Cu-6 wt.\% Ag Filamentary Nanocomposite. Acta Mater., 59, 1191-1197. https://doi.org/10.1016/j.actamat.2010.10.052

[11] Feng, Q., Song, L., Zeng, Y., Fang, Y., Meng, L., Liu, J. and Wang, H. (2015) Evolution of FCC/BCC Interface and Its Effect on the Strengthening of Severe Drawn Cu-3 wt.\% Cr. J. Alloys Compd., 640, 45-50.

https://doi.org/10.1016/j.jallcom.2015.03.226

[12] Stepanov, N.D., Kuznetsov, A.V., Salishchev, G.A., Khlebova, N.E. and Pantsyrny, V.I. (2013) Evolution of Microstructure and Mechanical Properties in $\mathrm{Cu}-14 \% \mathrm{Fe}$ Alloy During Severe Cold Rolling. Mater. Sci. Eng. A, 564, 264-272. https://doi.org/10.1016/j.msea.2012.11.121

[13] Liu, J.B., Meng, L. and Zeng, Y.W. (2006) Microstructure Evolution and Properties of Cu-Ag Microcomposites with Different Ag Content. Mater. Sci. Eng. A, 435-436, 237-244. https://doi.org/10.1016/j.msea.2006.07.125

[14] Liu, K.M., Jiang, Z.Y., Zhou, H.T., Lu, D.P., Atrens, A. and Yang, Y.L. (2015) Effect of Heat Treatment on the Microstructure and Properties of Deformation-Processed Cu-7Cr in situ Composites. J. Mater. Eng. Perform., 24, 4340-4345.

https://doi.org/10.1007/s11665-015-1747-z

[15] Deng, L.P., Yang, X.F., Han, K., Lu, Y.F., Liang, M. and Liu, Q. (2013) Microstructure and Texture Evolution of $\mathrm{Cu}-\mathrm{Nb}$ Composite Wires. Mater. Charact., 81, 124-133. https://doi.org/10.1016/j.matchar.2013.04.013

[16] Liu, K.M., Lu, D.P., Zhou, H.T., Atrens, A., Chen, Z.B., Zou, J. and Zeng, S.M. (2010) Influence of Ag Micro-Alloying on the Microstructure and Properties of $\mathrm{Cu}-7 \mathrm{Cr}$ in situ Composite. J. Alloys Compd., 500, L22-25.

https://doi.org/10.1016/j.jallcom.2010.03.246 
Submit or recommend next manuscript to SCIRP and we will provide best service for you:

Accepting pre-submission inquiries through Email, Facebook, LinkedIn, Twitter, etc. A wide selection of journals (inclusive of 9 subjects, more than 200 journals)

Providing 24-hour high-quality service

User-friendly online submission system

Fair and swift peer-review system

Efficient typesetting and proofreading procedure

Display of the result of downloads and visits, as well as the number of cited articles Maximum dissemination of your research work

Submit your manuscript at: http://papersubmission.scirp.org/

Or contact msce@scirp.org 